\title{
Effect of Sodium Chloride Replacement with Potassium Chloride on Quality Traits of Bicarbonate-Marinated Turkey Breast Meat
}

-Author(s)

Mudalal S' (iD https://orcid.org/0000-0002-6356-6891 Petracci M' (iD) https://orcid.org/0000-0002-5671-5676

Department of Nutrition and Food Technology, Faculty of Agriculture and Veterinary Medicine, An-Najah National University, P.O. Box 7, Nablus, Palestine.

" Department of Agricultural and Food Sciences, Alma Mater Studiorum, University of Bologna, Cesena, Italy 47521.

\section{Mail Address}

Corresponding author e-mail address Samer Mudalal

An-najah National University Faculty of Medicine and Health Sciences - Nutrition and food technology Nablus, P.O box 7 , Palestine Nablus 401 Palestine.

Phone: +97(0)597394807

Email: samer.mudalal@najah.edu

\section{- Keywords}

Chemical composition, water activity texture, sensory.

\section{ABSTRACT}

This study aims to evaluate the possibility to formulate low-sodium bicarbonate-marinated turkey breast meat. In total, 60 meat cuts (100 $\times 50 \times 30 \mathrm{~mm})$ were divided into four treatments: B1 $(0.5 \%$ sodium bicarbonate and $0 \%$ sodium chloride replacement), B2 (0.5\% sodium bicarbonate and $15 \%$ sodium chloride replacement), B3 (0.5\% sodium bicarbonate and 30\% sodium chloride replacement), and B4 (0.5\% sodium bicarbonate and $45 \%$ sodium chloride replacement). The results showed that sodium replacement up to $45 \%$ had no impact on texture (as represented by Allo-Kramer shear values) and water activity. After cooking, Group B1 exhibited the highest L* value (72.1) and the lowest $b *$ (6.6) when compared to other groups. In conclusion, replacing sodium chloride with potassium chloride up to $45 \%$ in the presence of sodium bicarbonate did not affect negatively several quality traits (sensory traits, composition, and texture, etc.).

\section{INTRODUCTION}

In the past few decades, there was a growing trend in meat industries to formulate free phosphate and low-sodium meat products due to increasing the consumer awareness about the adverse health implications of phosphates and excess sodium dietary intake. Sodium chloride is habitually used in meat products for several purposes such as improving water holding/binding capacity (WHCMBC), imparting the flavor, and increase microbiological stability (Aksu et al., 2003, Newson et al., 2013, U-chupaj et al., 2017). Excess sodium dietary intake is considered one of the significant risk factors for hypertension and cardiovascular diseases. Recent data showed that dietary sodium intake is still exceeding the recommended dietary allowance (Newson et al., 2013). Different strategies have been adopted to reduce sodium chloride in meat products (Doyle \& Glass, 2010). Using salt replacers (such as potassium, magnesium and calcium chloride) is considered one of the most common strategies. Potassium chloride has been intensively studied, and it was effective as a salt replacer in different meat products (Doyle \& Glass, 2010, Lee et al., 2012, Petracci et al., 2012).

In this context, phosphates in combination with sodium chloride habitually used to improve the water binding capacity of meat products. Different studies showed that excess dietary intake of phosphates have several adverse health implications such as Attention Deficit Disorder as well as allergic reaction in children (Hafer, 2002), increase the risk of osteoporosis (Anderson, 1996), disorder and damage in the kidney (Dikeman et al., 2003), and diarrhea (Berner \& Shike, 1988). Accordingly, the usage of phosphates has been reduced in some countries while in other countries; they have been banned (Sebranek et al., 2010). 
Several components have been suggested to replace phosphates in processed meat products. Recent studies showed that sodium bicarbonate might be considered as a promising component to replace phosphates. It was found that the adverse effect of Pale Soft Exudates (PSE) on the quality traits of pork and poultry meat has been alleviated by the addition of sodium bicarbonate. Moreover, several authors showed that bicarbonates could improve the product yield and tenderness (low shear force values) of pork meat (Sen et al., 2005; Sheard \& Tali, 2010). The effect of sodium bicarbonate on the quality traits of meat may be explained by the buffering capacity and ionic strength which was higher when compared to phosphates. A synergistic effect was found between sodium bicarbonate and phosphate where marinade performance and cooking yield were higher in comparison to using them separately (Petracci et al., 2012). In addition, bicarbonate increased water binding capacity in marinated meat (Saleem et al., 2014). Another study showed that sodium bicarbonate exhibited a similar effect on the quality traits of meat to phosphate treated meat (Sen et al., 2005)

All previous studies investigated the possibility to reduce sodium chloride in the presence of phosphates or other similar components. Until now, there are no available studies that examined the effect of replacing sodium chloride by potassium chloride in bicarbonatetreated meat products. This research aims to evaluate the impact of replacing sodium chloride by potassium chloride on the quality traits of bicarbonate-marinated turkey breast meat.

\section{MATERIALS AND METHODS}

Samples collection and preparation: 60 boneless, skinless turkey Pectoralis major muscles were collected from the same flock of 20-week old tom turkey from a local slaughterhouse in two replications. The meat was frozen for commercial use, and it was defrosted under commercial conditions using water spray nozzles. From each fillet, about $100 \mathrm{~g}$ of a parallelepiped meat cut (dimensions: $100 \times 50 \times 30 \mathrm{~mm}$ ) has been excised in the same direction of muscle fibers from the cranial part.

Marination process: the samples were divided into four different groups $(n=15)$ and marinated by using solutions described in Table 1. All meat samples in each group were marinated and tumbled (in continuous mode) by using a small-scale vacuum tumbler for 25 min (speed 20 rpm, 500 rounds) at pressure -0.95 bar.
Table - 1 Marination conditions at 25\% target level of marination. The added marinade solution was calculated based on $25 \%$ of the weight of meat for each group.

\begin{tabular}{lcccc}
\hline \multirow{2}{*}{ Ingredients } & \multicolumn{4}{c}{ Treatment groups } \\
\cline { 2 - 5 } & B1 & B2 & B3 & B4 \\
\hline \% sodium chloride* & 1.8 & 1.53 & 1.26 & 0.9 \\
\% replacement by potassium chloride* & 0 & 0.27 & 0.54 & 0.9 \\
\% sodium bicarbonate & 0.5 & 0.5 & 0.5 & 0.5 \\
\hline
\end{tabular}

*The percentage of sodium and potassium chloride was $1.8 \%$, to achieve replacements $0,15,30$, and $50 \%$ of sodium chloride by potassium chloride for B1, B2, B3, and B4 respectively.

Analysis of quality traits: For each raw sample, before marination: $\mathrm{pH}$, color values $\left(L^{*} a^{*} b^{*}\right)$, and proximate composition (moisture, protein, fat, and collagen) have been measured. While after marination: marinade uptake, purge loss, and color values were determined. Finally, after cooking: cooking loss, cooking yield, Allo-Kramer shear force, water activity, $\mathrm{pH}$, color values $\left(L^{*}, a^{*}, b^{*}\right)$, proximate composition (moisture, protein, fat, salt, and collagen), and sensory analysis (juiciness, saltiness, degree of fatness, texture, and overall acceptance) were assessed.

Minolta Chroma Meter (CR-410) was used to measure color values $\left(L^{*}, a^{*}, b^{*}\right)$ based on the Commission International de I'Eclairage (CIE) system with one dimension for luminance ( $L^{*}$-lightness) and two for color ( $a^{*}$-green to red; $b^{*}$-blue to yellow). Three color measurements were carried out on the surface of each sample using a head with a $8 \mathrm{~mm}$ measuring window, where the mean value of three measures was calculated.

For raw meat samples, $\mathrm{pH}$ was measured for a cut of meat adjacent to meat cut that was used for marination by, CA using hand-held $\mathrm{pH} /$ temperature meter (ISFET, Model \# IQ150, IQ Scientific Instruments, San Diego, USA). After cooking, the $\mathrm{pH}$ was measured by using a hand-held $\mathrm{pH} /$ temperature meter.

Marinated meat samples were packed under vacuum and cooked in a water bath at $80^{\circ} \mathrm{C}$ for about 80 min until core temperature arrived at $78^{\circ} \mathrm{C}$ and then samples were cooled in a refrigerated water bath.

The weight of each sample as raw (W1), after marination (W2), after $24 \mathrm{~h}$ of refrigerated storage (W3), and after cooking (W4) were recorded to calculate the following parameters in Table 2.

Chemical composition (moisture, protein and lipid contents) of breast meat was assessed using official methods of AOAC (AOAC, 1999). The percentage of moisture content was determined. About five grams minced meat sample was dried in a conventional oven at $105^{\circ} \mathrm{C}$ for $16 \mathrm{~h}$. Crude protein content 
Table 2 - Quality parameters that were employed to evaluate marination performances.

\begin{tabular}{lll}
\hline No & Parameters & Formula \\
\hline 1. & Marinade uptake $(\%)$ & $=\frac{(W 2-W 1)}{W 1} \times 100$ \\
2. & Purge loss (\%) & $=\frac{(W 2-W 3)}{W 2} \times 100$ \\
3. Cooking loss (\%) & $=\frac{(W 3-W 4)}{W 3} \times 100$ \\
4. Cooking yield (\%) & $=\frac{W 4}{W 1} \times 100$ \\
\hline
\end{tabular}

was estimated by the Kjeldahl method, while the intramuscular fat content was assessed by petroleum ether extraction using soxhlet method. Hydroxylproline was determined as a measure of collagen content using a colorimetric method (Kolar, 1990). About $4 \mathrm{~g}$ of finely minced meat was hydrolyzed with sulphuric acid in an air oven at $105^{\circ} \mathrm{C}$ for $16 \mathrm{~h}$. The colored compound of hydrolyzed hydroxylproline was formed by the interaction with chloramine and 4-dimethylaminobenzaldehyde. The absorbance was measured by UV-Visible Spectrophotometer (UV-1601; Shimadzu, Tokyo, Japan) at $558 \mathrm{~nm}$.

Cooked meat samples cut $(40 \times 20 \times 10 \mathrm{~mm})$ were used to measure Allo-Kramer Shear force using TA-Hdi Texture Analyzer (Stable Micro Systems Ltd., Godalming, Surrey, UK) equipped with load cell set 25 $\mathrm{kg}$ load cell and cross-head speed was $50 \mathrm{~cm} / \mathrm{min}$. The samples were sheared perpendicularly by ten blades set of Allo-Kramer to muscle fibers direction. Shear force was defined as kilograms shear per gram of sample (Bianchi et al., 2007).

Water activity $\left(a_{w}\right)$ was isothermally measured $(25 \pm$ $1^{\circ} \mathrm{C}$ ) by a water activity meter mod Aqualab (Decagon Devices Inc., Pullman, WA) that bases its measure on the chilled-mirror dew-point technique.

Sensory analysis was evaluated by 40 untrained panelists demographically characterized as follows: 45 and 55\% were males and females, respectively; $80 \%$ were from 20 to 30 years old, $15 \%$ were 30 to 40 years old, and $5 \%$ were older than 40 years. Four cooked meat samples (samples dimension: $20 \times 20 \times$
$10 \mathrm{~mm}$, about $30 \mathrm{~g}$ in weight) at room temperature were offered for each panelist according to a randomized block design. All samples had the same fiber directions. Each sample was scored by perceived saltiness, ranging from one (extremely unsalted) to seven (extremely salted). Also, juiciness, the degree of fatness, texture, and overall acceptance scored from one (extremely disliking) to seven (extremely liking).

\section{Statistical analysis}

Results about chemical composition and technological quality traits were analyzed by using two-way ANOVA taking into consideration treatments, replication and their interactions as principal effects. Sensory results were evaluated using a two-way ANOVA, treating a marination type as a fixed effect, while panelist and panelist by marination-type interactions (if any) as random effects. The differences between means were assessed by Duncan post hoc test at a significance level of 0.05 .

\section{RESULTS AND DISCUSSION}

The effect of different levels of sodium replacement by potassium chloride on chemical composition is shown in Table 3. The proximate composition did not show any significant differences between the groups. This result may indicate that sodium reduction in the presence of sodium bicarbonate did not affect the behavior of water evaporation, loss of soluble proteins, and fat melting during cooking.

Sensory attributes (juiciness, saltiness, the degree of fatness, texture, and overall acceptance) are shown in Table 4. Overall, there were no significant differences in all sensory attributes between the groups. The juiciness and texture are considered the most important quality traits of meat products. The texture is usually affected by several factors such as the composition of the product, $\mathrm{pH}$, temperature, and protein dissolution. Moreover, moisture and fat contents may change juiciness and texture (Xiong et al., 2006). Our results showed no significant difference in moisture and fat contents which may explain the absence of differences in juiciness and texture between

Table 3 - Proximate chemical composition (mean \pm standard error) for all treatments after cooking ( $\mathrm{n}=15$ for each group).

\begin{tabular}{|c|c|c|c|c|c|}
\hline \multicolumn{6}{|c|}{ Level of substitution ( $\mathrm{NaCl}$ : $\mathrm{KCl}$ ratio) } \\
\hline B4 (55:45) Mean \pm SEM & B3(70:30) Mean \pm SEM & B2 (85:15) Mean \pm SEM & B1(100:0) Mean \pm SEM* & & $p$-value \\
\hline $0.91 \pm 0.04$ & $0.95 \pm 0.08$ & $0.94 \pm 0.06$ & $0.92 \pm 0.05$ & Collagen (\%) & 0.31 \\
\hline $2.02 \pm 0.47$ & $1.49 \pm 0.53$ & $3.42 \pm 0.41$ & $2.35 \pm 0.31$ & Fat (\%) & 0.43 \\
\hline $71.45 \pm 0.73$ & $71.89 \pm 0.54$ & $70.25 \pm 0.62$ & $71.27 \pm 0.49$ & Moisture (\%) & 0.25 \\
\hline $26.11 \pm 0.69$ & $26.37 \pm 0.81$ & $25.81 \pm 0.64$ & $25.99 \pm 0.73$ & Protein (\%) & 0.73 \\
\hline
\end{tabular}

*Standard Error of Mean. 
the groups. The results of perceived saltiness and overall acceptance agreed with some previous studies (La Croix et al., 2015). Total acceptance of products is profoundly affected by salt perception (Tobin et al., 2012). In this context, it was found by several researchers that the reduction of sodium chloride may reduce consumer acceptance of meat products (Sofos 1983, Tobin et al., 2012).

Table 4 - Impact of different levels of $\mathrm{NaCl}$ replacement with $\mathrm{KCl}$ on sensory traits (mean \pm standard error) of marinated turkey breast meat $(\mathrm{n}$. of panelists $=40$ ).

\begin{tabular}{|c|c|c|c|c|c|}
\hline \multicolumn{6}{|c|}{ Level of substitution ( $\mathrm{NaCl}: \mathrm{KCl}$ ratio) } \\
\hline $\begin{array}{c}\text { B4 (55:45) } \\
\text { Mean } \pm \text { SEM }\end{array}$ & $\begin{array}{c}\text { B3(70:30) } \\
\text { Mean } \pm \text { SEM }\end{array}$ & $\begin{array}{c}\text { B2 }(85: 15) \\
\text { Mean } \pm \text { SEM }\end{array}$ & $\begin{array}{c}\text { B1(100:0) } \\
\text { Mean } \pm \text { SEM }\end{array}$ & & $p$-value \\
\hline $3.40 \pm 0.51$ & $3.60 \pm 0.52$ & $5.00 \pm 0.84$ & $5.20 \pm 1.31$ & Juiciness & 0.11 \\
\hline $4.60 \pm 0.68$ & $5.00 \pm 1.05$ & $5.40 \pm 0.81$ & $5.00 \pm 0.71$ & Saltiness & 0.65 \\
\hline $4.00 \pm 0.77$ & $3.2 \pm 0.97$ & $2.8 \pm 0.91$ & $3.2 \pm 1.2$ & Degree of fatness & 0.33 \\
\hline $5.50 \pm 0.37$ & $5.20 \pm 0.66$ & $5.20 \pm 0.66$ & $6.8 \pm 0.58$ & Texture & 0.13 \\
\hline $4.55 \pm 0.45$ & $4.20 \pm 0.92$ & $5.40 \pm 1.03$ & $4.6 \pm 1.03$ & Overall acceptance & 0.42 \\
\hline
\end{tabular}

The main technological traits are shown in Table 5. The variation in color values between the samples were in agreements with previous studies (Fletcher, 1999). Several researchers have found that there was a correlation between $\mathrm{pH}$ and the color of meat and both characteristics affect the different quality traits of meat (Fletcher, 1999). Therefore, to minimize the effect of $\mathrm{pH}$ and color from the treatment effect, the samples were redistributed before treatments into four different groups to have no significant difference in $\mathrm{pH}$ values and color values $\left(L^{*}, a^{*}, b^{*}\right)$. The lightness $\left(L^{*}\right)$ range of raw meat samples was 55.5859.78, which was in agreement with lightness values from previous studies ( $L * 38-57)$ (Barbut, 1998), $\left(L^{*}\right.$ 41-63) (Owens, 2000), and (L*35-55) (Petracci et al., 2012).

Table 5 - Effect of different levels of $\mathrm{NaCl}$ replacement with $\mathrm{KCl}(100: 0,85: 15,70: 30$, and 55:45 $\mathrm{NaCl}: \mathrm{KCl}$ ratio) on marination performances and quality traits (mean \pm standard error) of marinated turkey breast meat ( $n=20 / g r o u p)$.

\begin{tabular}{|c|c|c|c|c|c|}
\hline \multirow[b]{2}{*}{$\begin{array}{l}\text { B4 }(55: 45) \\
\text { Mean } \pm \text { SEM }\end{array}$} & \multicolumn{2}{|c|}{ Level of substitution ( $\mathrm{NaCl}: \mathrm{KCl}$ ratio) } & & \multirow[b]{2}{*}{ Parameters } & \multirow[b]{2}{*}{$p$-value } \\
\hline & $\begin{array}{c}\text { B3(70:30) } \\
\text { Mean } \pm \text { SEM }\end{array}$ & $\begin{array}{c}\text { B2 }(85: 15) \\
\text { Mean } \pm \text { SEM }\end{array}$ & $\begin{array}{c}\text { B1(100:0) } \\
\text { Mean } \pm \text { SEM }\end{array}$ & & \\
\hline & & & & Lightness index & \\
\hline $57.54 \pm 0.46$ & $55.58 \pm 0.57$ & $59.49 \pm 0.82$ & $59.78 \pm 0.67$ & $\mathrm{~L}_{\mathrm{r}}$ & 0.075 \\
\hline $53.27^{a} \pm 0.55$ & $51.9^{\mathrm{ab}} \pm 0.52$ & $50.8^{\mathrm{ab}} \pm 0.47$ & $48.95^{b} \pm 0.46$ & $L_{m}$ & 0.051 \\
\hline \multirow[t]{2}{*}{$72.13^{\mathrm{a}} \pm 0.67$} & $70.78^{\mathrm{ab}} \pm 0.75$ & $69.77^{b c} \pm 0.72$ & $68.42^{c} \pm 0.66$ & $\mathrm{~L}_{c}$ & 0.001 \\
\hline & & & & Yellowness index & \\
\hline $2.81 \pm 0.15$ & $2.96 \pm 0.32$ & $2.49 \pm 0.25$ & $2.95 \pm 0.21$ & $a_{r}$ & 0.523 \\
\hline $2.22 \pm 0.19$ & $2.48 \pm 0.28$ & $2.83 \pm 0.23$ & $3.2 \pm 0.18$ & $a_{m}$ & 0.082 \\
\hline \multirow[t]{2}{*}{$4.4 \pm 0.33$} & $4.55 \pm 0.29$ & $5.01 \pm 0.33$ & $4.78 \pm 0.32$ & $a_{c}$ & 0.392 \\
\hline & & & & Redness index & \\
\hline $3.81 \pm 0.35$ & $4.04 \pm 0.19$ & $2.51 \pm 0.26$ & $1.99 \pm 0.15$ & $b_{y}$ & 0.123 \\
\hline $1.64 \pm 0.34$ & $1.67 \pm 0.16$ & $2.45 \pm 0.21$ & $1.92 \pm 0.15$ & $b_{m}$ & 0.918 \\
\hline $6.6^{c} \pm 0.38$ & $7.51^{b c} \pm 0.56$ & $8.57^{\mathrm{ab}} \pm 0.51$ & $9.61^{\mathrm{a}} \pm 0.46$ & $b_{c}$ & 0.001 \\
\hline $5.66 \pm 0.01$ & $5.66 \pm 0.01$ & $5.66 \pm 0.02$ & $5.66 \pm 0.01$ & $\mathrm{pH}_{\mathrm{r}}$ & 0.947 \\
\hline $6.29 \pm 0.02$ & $6.31 \pm 0.03$ & $6.26 \pm 0.04$ & $6.25 \pm 0.03$ & $\mathrm{pH}_{\mathrm{c}}$ & 0.385 \\
\hline $19.19 \pm 0.61$ & $18.64 \pm 0.54$ & $16.46 \pm 0.32$ & $18.39 \pm 0.25$ & Marinade uptake \% & 0.647 \\
\hline $1.52^{c} \pm 0.10$ & $4.01^{b} \pm 0.18$ & $5.72^{\mathrm{a}} \pm 0.11$ & $6.06^{a} \pm 0.21$ & Purge loss $\%$ & $<0.001$ \\
\hline $17.83^{\mathrm{a}} \pm 0.18$ & $16.15^{b} \pm 0.21$ & $15.46^{b} \pm 0.33$ & $16.4^{\mathrm{ab}} \pm 0.54$ & Cooking loss \% & 0.005 \\
\hline $96.34 \pm 0.33$ & $95.44 \pm 0.53$ & $93.33 \pm 0.44$ & $92.93 \pm 0.41$ & Yield \% & 0.144 \\
\hline $2.97 \pm 0.33$ & $3.11 \pm 0.40$ & $2.78 \pm 0.27$ & $2.66 \pm 0.19$ & Shear force (kg/g) & 0.759 \\
\hline $0.9862 \pm 0.001$ & $0.9858 \pm 0.001$ & $0.985 \pm 0.001$ & $0.9842 \pm 0.001$ & Water activity & 0.738 \\
\hline
\end{tabular}

a-c Means within a row followed by different superscript letters differ significantly $(p<0.05)$. Lowercase letters in color indexes described as r: raw, m: marinated, and c: cooked.

Our findings showed that the obtained range of lightness and $\mathrm{pH}$ values for meat samples were classified as Pale Soft Exudative (meat is considered PSE when $L^{*}>53$ ). The $\mathrm{pH}$ for raw meat in all groups was 5.66 which is less than the suggested borderline of PSE meat $(\mathrm{pH}<5.7)$. Low $\mathrm{pH}$ is responsible for the increase of light scattering which leads to more pale flesh (Barbut, 1998), and average low measured $\mathrm{pH}$ values were linked with high lightness value. 
After marination, $L$ * range was $48.95-53.27$ which is very close to normal meat range $\left(48<L^{*}<53\right.$ ) (Qiao et al., 2002). This result can be justified due to the addition of sodium bicarbonate at level $0.5 \%$ which is generally caused by about 0.3 , an increase in $\mathrm{pH}$ value (Mudalal et al., 2013). Bicarbonates have high buffering capacity and ionic strength. The lightness of marinated meat samples in group B1 was significantly lower than group B4 (48.95 vs. 53.27) while group B2 and B3 showed intermediate values. There were no significant differences between different marinated groups in $a^{*}$ (redness) and $b^{*}$ (yellowness) values. After cooking, group B1 showed significantly lightness value higher than B3 and B4 (68.42 vs. 70.78 and $72.13, p<0.05)$ respectively, while group B2 and B3 showed intermediate values. The different trends in $L$ * values between groups after marination was similar after cooking. Cooked samples from different groups did not show any significant difference in $a^{*}$ values. There was a significant difference in $b^{*}$ values after cooking between the groups. Group B4 had lower $b^{*}$ value than $B 1$ and $B 2$ (6.60 vs. 9.61 and $8.57, p<0.05$ ) respectively but group $B 2$ and $B 3$ exhibited intermediate values when compared with other groups.

After cooking, there were no significant differences in $\mathrm{pH}$ between groups. This result may be explained by the absence of any significant differences in marinade uptake, which means that the quantity of sodium bicarbonate (the dominant effect on $\mathrm{pH}$ ) that was absorbed by each group was similar. It was found that replacing sodium chloride by potassium chloride had a significant impact on purge loss. Marinade uptake, purge loss, cooking loss, and cooking yield were used as an indicator for water hold capacity (WHC). WHC can be defined as the ability of raw and processed meat to hold either natural or added water (Hamm 1986). Group B4 exhibited the lowest value of purge loss when compared to other groups. Purge loss in group B4 and B3 were significantly lower in comparison to group B2 and B1 (1.52 and $4.00 \%$ vs. 5.72 and $6.06 \%$, $p<0.005)$, respectively. Our results show that purge loss decreased by replacing sodium chloride with potassium chloride. In general, drip loss is affected by changes in fiber structure and myofilament organization as well as permeability of cell member. Drip loss increases by myofilament shrinkage and reduction in extracellular spaces (Huff-Lonergan et al., 2005). In our study, it is not well known why replacing sodium chloride with potassium chloride led to a reduction in purge loss.

Samples from group B4 exhibited significantly higher cooking loss when compared with group B3 and
B4 while the other groups showed intermediate values if compared with group B1. Even though there were significant differences in the cooking loss, cooking yield did not show any significant differences. Cooking loss (which is usually water and soluble matter) induced by protein denaturation and breakdown during cooking which reduces capillary forces (Huff-Lonergan et al., 2005). Replacing sodium chloride with potassium chloride at different levels (up to $45 \%$ ) in the presence of sodium bicarbonate did not show any effect on texture (as represented by Allo-Kramer shear force values) and water activity. This can be explained due to the absence of any differences in marinade uptake and moisture content which affects sharply fiber density and quantity of free water.

In general, replacing sodium chloride with potassium chloride up to $45 \%$ did not affect negatively the main technological properties (such as $\mathrm{pH}$, marinade uptake, purge loss, cooking yield, shear force, water activity, $b^{*}$ and $a^{*}$ values). The effect was just confined to lightness and cooking loss. Therefore, replacing sodium chloride with potassium chloride in the presence of sodium bicarbonate showed better performance than in the presence of phosphates if compared to previous studies (Xiong, 1999, Petracci et al., 2012). Sodium chloride usually dissociates into sodium and chloride ions when added to meat. It is well known that chloride ions interact with myosin stronger than sodium ions which explains why it is possible to replace sodium chloride by potassium chloride without impairing the technological properties. But this replacement was limited to certain levels (30\%) in the presence of phosphate as mentioned by several previous studies (Lee et al., 2012, Jin et al., 2013). On the contrary, our findings showed that it was possible to replace up to $45 \%$ in the presence of sodium bicarbonate.

This high performance of sodium bicarbonate may be explained due to differences in buffering capacity and ionic strength. These findings were proven from previous studies where the addition of bicarbonate lead to a higher increase in $\mathrm{pH}(0.7$ vs. $0.3 \mathrm{pH}$ units) when compared with phosphates at the same level. In our findings, bicarbonate was able to increase the $\mathrm{pH}$ of meat by 0.65 unit which was in agreement with previous studies (Petracci et al., 2012). Moreover, the addition of sodium bicarbonate may induce more the effect of capillary forces because it was found that carbon dioxide was generated during cooking which imparted more porosity to the microstructure of meat (Garcia et al., 2002). 
The range of marinade uptake (16.46-19.19\%), cooking loss (15.46-17.83\%), and cooking yield (92.93-96.34\%) which were obtained in this study; were in agreement with previous studies (Sheard \& Tali 2010, Petracci et al., 2012). Replacing of sodium chloride by potassium chloride up to $45 \%$ had no significant impact on water activity. These results were in agreement with Garcia et al. (2002). It means that potassium chloride had a similar effect on water activity as well as sodium chloride. The amount of solutes in water is the main factor that affects water activity.

Measuring the effect of treatment on color properties is very important; because color can affect consumer preferences and acceptance of poultry meat (Qiao et al., 2002). By pooling the results considering the effect of marination and cooking in color values
Table 6, it was found that a* values after cooking significantly increased (4.68 vs. 2.80 and 2.68) in comparison to raw and marinated meat. There were no significant differences in $a^{*}$-values between raw and marinated chicken. This result may be explained due to the increase in $\mathrm{pH}$ as result of sodium bicarbonate addition which reduces myoglobin denaturation during cooking (Trout, 1989). Cooked meat samples had significantly higher values of $L^{*}$ and $b^{*}$ than raw and marinated meat samples. $L^{*}$ and $b^{*}$ have been significantly decreased after marination if compared with raw meat samples while $a^{*}$-value did not change.

The reduction in yellowness $\left(b^{*}\right)$ may be due to the dilution effect by the absorption of marinade solution. In addition, by the absorption of marinade solution and shift $\mathrm{pH}$ to higher value led to lower fiber

Table 6 - Effect of the process and different levels of $\mathrm{NaCl}$ replacement with $\mathrm{KCl}(100: 0,85: 15,70: 30$, and 55:45 NaCl: $\mathrm{KCl}$ ratio) on color indexes (mean \pm standard error) of marinated turkey breast meat.

\begin{tabular}{|c|c|c|c|c|}
\hline \multicolumn{5}{|c|}{ Color indexes } \\
\hline & & $L^{*}$ & $a^{*}$ & $b^{*}$ \\
\hline \multirow{4}{*}{ Process } & Raw & $58.10^{b} \pm 0.51$ & $2.80^{b} \pm 0.13$ & $3.09^{b} \pm 0.36$ \\
\hline & Marinated & $51.22^{c} \pm 0.51$ & $2.68^{b} \pm 0.13$ & $1.92^{c} \pm 0.36$ \\
\hline & Cokeed & $70.30^{a} \pm 0.52$ & $4.68^{a} \pm 0.14$ & $8.05^{\mathrm{a}} \pm 0.37$ \\
\hline & Probability & $<0.005$ & $<0.005$ & $<0.005$ \\
\hline \multirow{5}{*}{ Treatment } & B1 & $58.83 \pm 0.60$ & $3.61 \pm 0.16$ & $4.39 \pm 0.43$ \\
\hline & B2 & $60.01 \pm 0.59$ & $3.44 \pm 0.15$ & $4.50 \pm 0.42$ \\
\hline & B3 & $59.41 \pm 0.59$ & $3.33 \pm 0.15$ & $4.41 \pm 0.42$ \\
\hline & B4 & $60.98 \pm 0.57$ & $3.14 \pm 0.14$ & $4.02 \pm 0.42$ \\
\hline & Probability & 0.146 & 0.819 & 0.114 \\
\hline
\end{tabular}

Means with different letters $(a-c)$ within in the same column indicate significant differences $(p<0.05)$.

density; therefore light scattering decreases leading to low $L *$ values. The effect of the marination process on color values was generally in agreement with previous studies (Fletcher, 1999, Petracci et al., 2012)

Finally, there was no significant effect of different bicarbonate/sodium chloride treatments on color values $\left(L^{*}, a^{*}, b^{*}\right)$.

\section{CONCLUSION}

In conclusion, our study showed that there is a possibility to formulate no-added phosphate and low sodium marinated turkey breast products up to a certain level without impairing the quality traits. Replacing sodium chloride with potassium chloride up to $30 \%$ had no adverse effect on any quality traits.

\section{ACKNOWLEDGMENT}

This work has been financed from the Deanship of Scientific Research at An-Najah National University under project number ANNU-MoHE-1819-Sc012.

\section{REFERENCES}

Addeen A, Benjakul S, Prodpran T. Slaughtering method affects lipid oxidation, microbial quality, textural properties and the volatile profile of chicken patties during storage. Emirates Journal of Food and Agriculture 2017;29:387-95.

Aksu M, Aktaş N, Kaya M. The Influence of Marination with Different Salt Concentrations on the Tenderness, Water Holding Capacity and Bound Water Content of Beef. Turkish Journal of Veterinary and Animal Science 2003;27:1207-1211

Anderson JB. Calcium, phosphorus, and human bone development. Journal of Nutrition 1996;126:1153-1158.

AOAC. Association of Official Analytical Chemists. Official methods of analysis of association of official analytical chemists. $15^{\text {th }}$ ed. Washington; 1990

Barbut S. Estimates of the magnitude of the PSE problem in poultry - a review. Journal of Muscle Foods 1998;9:35-49.

Berner YN, Shike M. Consequences of phosphate imbalance. Annual Review of Nutrition 1998;8:121-148.

Bianchi M, Petracci M, Pascual M, Cavani C. Comparison between AlloKramer and Warner-Bratzler devices to assess rabbit meat tenderness. Italian Journal of Animal Science 2007:6:749-751.

Dikeman ME, Hunt MC, Addis PB, Schoenbeck HJ, Pullen M, Katsanidism $\mathrm{E}$, et al., Effects of post exsanguination vascular infusion of cattle with 
a solution of saccharides, sodium chloride, and phosphates or with calcium chloride on quality and sensory traits of steaks and ground beef. Journal of Animal Science 2003;81:156-166.

Doyle ME, Glass KA. Sodium reduction and its effect on food safety, food quality, and human health. Comprehensive Reviews in Food Science and Food Safety 2010;9:44-56.

Fletcher DL. Broiler breast meat color variation, $\mathrm{pH}$ and texture. Poultry Science 1999;78:1323-1327.

Garcia ML, Dominguez R, Galvez MD, Casas C, Selgas MD. Utilization of cereal and fruit fibers in low fat dry fermented sausages. Meat Science 2002;60:227-236.

Hafer $\mathrm{H}$. The hidden drug: dietary phosphate. Heidelberg: Hüthig Verlagsgemeinschaft; 2002. p.1-110.

Hamm R. Functional properties of the myofibrillar system and their measurements. In: Bechtel PJ, editor. Muscle as food. New York: Academic Press; 1986. p.135-199.

Huff-Lonergan EJ, Lonergan S. Mechanisms of water-holding capacity of meat:The role of postmortem biochemical and structural changes. Meat Science 2005;71:194-204.

Jin SK, Kim IS, Jeong JY, Kang SN, Shin DK, Kim GD. Influences of partial replacement of sodium chloride with potassium chloride, potassium lactate and calcium ascorbate on quality characteristics of cooked pork ham during cold storage. Journal of Agriculture and Life Science 2013;47:93-102.

Kolar K. Colorimetric determination of hydroxyproline as a measure of collagen content in meat and meat products: NMKL collaborative study. Journal of Association of Official Analytical Chemists 1999;73:54-57.

La Croix KW, Fiala SC, Colonna AE, Durham CA, Morrissey MT, Drum DK, et al., Consumer detection and acceptability of reduced-sodium bread. Public Health Nutrition 2015;18:1412-1418

Lee YS, Zhekove ZG, Owens CM, Kim M, Meullenet JF. Effects of partial and complete replacement of sodium chloride with potassium chloride on the texture, flavor, and water-holding capacity of marinated broiler breast fillets. Journal of Texture Studies 2012;43:124-132.

Mudalal S, Petracci M, Rocculi P, Tappi S, Cavani C. Comparison between the quality traits of phosphate and bicarbonate-marinated chicken breast fillets cooked under different heat treatments. Food and Nutrition Science 2013;5:35-44.

Newson RS, Elmadfa I, Biro GY, Cheng Y, Prakash V, Rust P, et al., Barriers for progress in salt reduction in general population. An international study. Appetite 2013;71:22-31.

Owens CM, Hirschler EM, McKee SR, Martinez-Dawson R, Sams AR. The characterization and incidence of pale, soft, exudative turkey meat in a commercial plant. Poultry Science 2000;79:553-558.
Petracci M, Laghi L, Rocculi P, Rimini S, Panarese V, Cremonini MA, et al, The use of sodium bicarbonate for marination of broiler breast meat. Poultry Science 2012;91:526-534.

Qiao M, Fletcher DL, Smith DP, Northcutt JK. Effects of raw broiler breast meat color variation on marination and cooked meat quality. Poultry Science 2002;81:276-280

Rasmussen MD, Bjerring M, Justesen $\mathrm{P}$, Jepsen L. Milk quality on Danish farms with automatic milking systems. Journal of Dairy Science 2002;85:2869-2878.

Saleem R, Absarul H, Riaz A. Changes in some biochemical indices of stability of broiler chicken actomyosin at different levels of sodium bicarbonate in presence and absence of sodium chloride. International Journal of Food Properties 2015;18:1373-1384.

Sebranek JG. Basic curing ingredients. In: Tarte R, editor. Ingredients in meat. New York: Springer-Verlag; 2009.

Sen AR, Naveena BM, Muthukumar M, Babji Y, Murthy TRK. Effect of chilling, polyphosphate, and bicarbonate on quality characteristics of broiler breast meat. British Poultry Science 2005;46:451-456

Sheard PR, Tali A. Injection of salt, tripolyphosphate, and bicarbonate marinade solutions to improve the yield and tenderness of cooked pork loin. Meat Science 2010;71:753-754.

Sofos JN. Effects of reduced salt $(\mathrm{NaCl})$ levels on sensory evaluation of frankfurters. Journal of Food Science 1983;48:1692-1696.

Tobin BD, O'Sullivan MG, Hamill RM, Kerry JP. Effect of varying salt and fat levels on the sensory and physiochemical quality of frankfurters. Meat Science 2012;92:659-666.

Trout GR. Variation in myoglobin denaturation and color of cooked beef, pork and turkey meat as influenced by $\mathrm{pH}$, sodium chloride, sodium tripolyphosphate and cooking temperature. Journal of Food Science $1989 ; 54: 536-544$

U-chupaj J, Malila Y, Petracci M, Benjakul S, Visessanguan W. Effect of tumbling marination on marinade uptake of chicken carcass and parts quality. Brazilian Journal of Poultry Science 2017;19(1):61-68.

Xiong R, Cavitt LC, Meullenet JF, Owens CM. Comparison of Allo-Kramer, Warner-Bratzler and razor blade shears for predicting sensory tenderness of broiler breast meat. Journal of Texture Studies 2006;37:179-199.

Xiong YL, Kuspski DR. Time-dependent marinade absorption and retention, cooking yield, and palatability of chicken fillets marinated in various phosphate solutions. Poultry Science 1999;78:1053-1059. 
